\title{
I n-hospital mortality and length-of-stay in a cohort of ED patients admitted to internistic units
}

\author{
Alfredo De Giorgi ${ }^{1}$, Fabio Fabbian ${ }^{1}$, J adran Ferro ${ }^{1}$, Alessandra Mallozzi Menegatti ${ }^{1}$, Raffaella \\ Salmi ${ }^{2}$, Roberto Melandri ${ }^{3}$, Andrea Gardini ${ }^{1}$, Gabriele Rinaldi ${ }^{1}$, Massimo Gallerani ${ }^{4}$, Roberto \\ Manfredini $^{1}$
}

1. Unit of Clinica Medica, Azienda Ospedaliera-Universitaria (AOU) of Ferrara, Italy. 2. Department of Medicine, 2nd Unit of Internal Medicine, AOU of Ferrara, Italy. 3. Emergency Department, AOU of Ferrara, Italy. 4. 1st Unit of Internal Medicine, AOU of Ferrara, I taly.

Correspondence: Prof. Roberto Manfredini. Address: Unit of Clinica Medica, Department of Medicine, Azienda Ospedaliera-Universitaria of Ferrara, via Aldo Moro 8, 44124 Cona (Ferrara), Italy. E-mail: roberto.manfredini@unife.it

Received: July 22, 2013

DOI : $10.5430 /$ jha.v3n2p42
Accepted: September 16, 2013

URL: http://dx.doi.org/10.5430/jha.v3n2p42

\section{Abstract}

Background: Several life-threatening acute diseases exhibit precise preferred times of onset, during the day (morning), the month or season of the year (winter), and the day of the week (Monday). Moreover, admission to the hospital during nighttime and weekend (WE) is associated with increased risk of in-hospital mortality (IHM) and length-of-hospital stay (LOS). Since most of these data have been obtained in North American settings, the aim of this study was to verify also in an Italian setting whether some factors related to ED evaluation, including time of arrival, and disease's severity evaluated by a colour code, could be associated with IHM and LOS in ED patients admitted to internal medicine units.

Methods: This study was conducted between January 1, 2010 and July 31, 2012, at the St Anna Hospital of Ferrara. We analyzed age, sex, time of arrival to the ED, ED boarding time, and triage colour code of all patients admitted to the Department of Medicine. Friday to midnight Sunday was considered as WE, and the nine main national festive days were always considered as Sunday-WE. Thus, the time period was classified into holidays (WE + festive days) and weekdays (WD), and daytime (8:00 am - 8:00 pm) and nighttime (8:00 pm - 8:00 am). IHM and LOS were assumed as primary and secondary objectives, respectively. Patients were classified into deceased and survivors, and LOS was classified depending on length lower or higher than the median (seven days). T-test, chi-squared test, U Mann-Whitney test, and logistic regression analysis were performed.

Results: During the 18-month period, 13,237 consecutive patients visiting the ED (43.4\% males, mean age $74.8 \pm 13.6$ years, $56.6 \%$ females, mean age $78.0 \pm 13.3$ years), were considered. IHM was related to: time of admission (daytime vs. nighttime, $p=.015$; WE vs. WD, $p=.026$, holidays vs. no holidays, $p=.021)$, colour code $(p<.001)$, and age $(p<.001)$. Multivariate analysis showed an independent association with IHM for colour code $(p<.001)$, and age $(p<.001)$. LOS $>7$ days was related to: time of admission (daytime vs. nighttime, $p<.001$; WE or WD, $p=.001$; holidays vs. no holidays, $p$ $=.002)$. Furthermore, $\operatorname{LOS}>7$ days depended on both colour code of admission $(p<.001)$, and age $(p<.001)$. Multivariate analysis showed a significant correlation with LOS $>7$ days for yellow colour code $(p<.001)$, and age $(p<.001)$.

Conclusions: Although several factors, such as admission colour code and age, influence some parameters of clinical outcome, i.e., IHM and LOS, a striking weekend effect is not evident in a cohort of consecutive patients admitted to an Italian Medical Department, characterized by intermediate-high level of urgency. 


\section{Key words}

In-hospital mortality, Length-of-stay, Emergency department, Daytime admission, Nighttime admission, Internal medicine

\section{Introduction}

Several life-threatening acute diseases seem to exhibit precise preferred times of onset, characterized by highest risk, during the hours of the day (morning), month or season of the year (winter), and day of the week (Monday) ${ }^{[1-13]}$. In particular, admission to the hospital during nighttime and weekend (WE) was associated with increased risk of in-hospital mortality (IHM) and length-of-hospital stay (LOS) in acute care hospitals in Canada and England ${ }^{[14,15]}$, and an increased risk has been recently reported to be associated with duration of visits in the $\mathrm{ED}^{[16]}$. Most studies, however, have been obtained in North American settings, but, to the best of our knowledge, no data are available for Italian settings. Thus, the aim of this study was to verify whether some factors related to ED evaluation, including time of arrival, and disease's severity evaluated by a colour code, could be associated with IHM and LOS in patients arriving to the ED and then admitted to internal medicine units.

\section{Subjects and methods}

The region Emilia Romagna (RER), located in north-eastern Italy, with a surface of $22,124 \mathrm{Km}^{2}$ and a population of $\approx$ 4.000,000, is administratively divided into nine provinces (Piacenza, Parma, Reggio Emilia, Modena, Bologna, Ferrara, Ravenna, Forlì-Cesena, Rimini). The Italian National Health Service (NHS), that provides free and equal health care access to all citizens, is controlled by regional governments and administered by local health authorities. RER includes eleven local health authorities (Piacenza, Parma, Reggio Emilia, Modena, Bologna, Imola, Ferrara, Ravenna, Forlì, Cesena, Rimini), five Teaching Hospitals (Parma, Reggio Emilia, Modena, Bologna, Ferrara) and one Research Orthopedic Institute (Bologna), with $\approx 17,000$ beds for acute patients. The province of Ferrara $(\approx 350,000$ inhabitants, mean age 47.3 years, $25.9 \%>65$ years) is served by one Teaching Hospital (hub center) and three community hospitals (spoke centers, $\approx 200$ beds/each). Local economy is mainly agriculture-based, and in minor part industrial.

This study was conducted between January 1, 2010 and July 31, 2012, at the St Anna Hospital of Ferrara, a 600-bed tertiary care teaching hospital, with a yearly ED patients flow of approximately 76,000 . We analyzed age, sex, time of arrival to the ED, ED waiting time, and colour-code of all patients admitted to the Department of Medicine. In our hospital, this Department consists of four internal medicine units, and one unit each of infectious diseases, geriatrics, and gastroenterology. The Department of Medicine alone accounts for about one-third of all hospital admissions. As in all Italy, the ED triage assessment is based on a colour-code scale basis, with highest priority given to red code, followed by yellow, green, and white. The triage assessment is performed by expert nurses, with specific training and experience. Both medical and nursing staff of the hospital is permanent, with replacements (e.g., festive days or holidays) warranted by apposite rotations among the entire staff. As temporal definitions, midnight Friday to midnight Sunday was considered as WE, and the nine main national festive days were always considered as Sunday-WE. Thus, the time period was classified into holidays (WE + festive days) and weekdays (WD), and daytime (8:00 am - 8:00 pm) and nighttime (8:00 pm - 8:00 am). IHM and LOS were assumed as primary and secondary objectives, respectively.

The results are presented as mean $\pm S D$ or percentages as appropriate. Patients were classified into deceased and survivors, and LOS was classified depending on length lower or higher than the median (seven days). Clinical parameters were compared in the two groups by t-test, chi-squared and Mann-Whitney U test as appropriate. In order to evaluate which variables were independently associated with IHM and LOS $>7$ days, logistic regression analysis was performed, with age, sex, time of ED arrival, ED boarding time, and colour code taken as the independent variables. A value of $p<.05$ was considered statistically significant. SPSS for Windows was used to analyze the data (SPSS, Version 13, SPSS Inc., Chicago, IL, USA).

Published by Sciedu Press 


\section{Results}

During the considered period, 13,237 consecutive patients visiting the ED (mean age $76.6 \pm 13.5$ years; $43.4 \%$ males, mean age $74.8 \pm 13.6$ years, $56.6 \%$ females, mean age $78.0 \pm 13.3$ years, $p<.001$ ), were admitted to the Department of Medicine. The preponderance of the female sample is given by the great percentage of old and very old inhabitants of Ferrara (3,500 people aged $>90$ years), with significant presence of widows. Again, only 178 women $(2.3 \%)$ were aged $<$ 40 years (child bearing age). Patients' and ED admission characteristics are reported in Table 1.

Table 1. Main characteristics of the 13,237 subjects investigated

\begin{tabular}{|l|l|}
\hline Mean $( \pm S D)$ age (years) & $76.6 \pm 13.5$ \\
\hline Males & $5739(43.4 \%)$ \\
\hline Females & $7498(56.6 \%)$ \\
\hline Daytime & $9481(71.6 \%)$ \\
\hline Weekdays & $9788(73.9 \%)$ \\
\hline Holiday & $3667(27.7 \%)$ \\
\hline Green code & $3257(24.6 \%)$ \\
\hline Yellow code & $9157(69.2 \%)$ \\
\hline Red code & $823(6.2 \%)$ \\
\hline Sunday & $1664(12.6 \%)$ \\
\hline Monday & $2217(16.7 \%)$ \\
\hline Tuesday & $1940(14.7 \%)$ \\
\hline Wednesday & $1904(14.4 \%)$ \\
\hline Thursday & $1890(14.3 \%)$ \\
\hline Friday & $1837(13.9 \%)$ \\
\hline Saturday & $1785(13.5 \%)$ \\
\hline Mean $( \pm S D)$ LOS (days) & $8.9 \pm 8.0$ \\
\hline
\end{tabular}

\subsection{I n-hospital mortality}

Univariate analysis (see Table 2) showed that IHM was related to time of admission (daytime: 74.5\% vs. 71.3\%, nighttime: $25.5 \%$ vs. $28.7 \%, p=.015$ ), WE or WD (WE: $28.6 \%$ vs. $25.8 \%$, WD: $71.4 \%$ vs. $74.2 \%, p=.026$ ), and holidays (holidays: 30.4\% vs. $27.4 \%$, no holidays: $69.6 \%$ vs. $72.6 \%, p=.021)$. Furthermore, IHM was in relation with colour code of admission (green: $3.9 \%$, yellow: 9.5\%, red: $41.7 \%, p<.001$ ), and patients' age $(76.2 \pm 13.6$ vs. $80.2 \pm 12.0, p<.001)$. Thus, deceased subjects were older, more frequently admitted during daytime, WE and holiday, and characterized by a red colour-code.

Table 2. Univariate association for primary objective (IHS)

\begin{tabular}{llll}
\hline & Discharged $(\mathbf{n}=\mathbf{1 1}, \mathbf{9 0 1})$ & Deceased $(\mathbf{n}=\mathbf{1 , 3 3 6})$ & $\boldsymbol{p}$ \\
\hline Age (years) & $76.2 \pm 13.6$ & $80.2 \pm 12.0$ & $<.001$ \\
Daytime & $71.3 \%$ & $74.5 \%$ & .015 \\
Nighttime & $28.7 \%$ & $25.5 \%$ & .026 \\
Weekend & $25.8 \%$ & $28.6 \%$ & \\
Weekday & $74.2 \%$ & $71.4 \%$ & .021 \\
Holiday & $27.4 \%$ & $30.4 \%$ & \\
No holiday & $72.6 \%$ & $69.6 \%$ & $<.001$ \\
Green code & $26.3 \%$ & $9.5 \%$ & \\
Yellow code & $69.7 \%$ & $64.8 \%$ & \\
Red code & $4 \%$ & $25.7 \%$ & \\
\hline
\end{tabular}


Table 2. (continued.)

\begin{tabular}{llll}
\hline & Discharged $(\mathbf{n}=\mathbf{1 1 , 9 0 1})$ & Deceased $(\mathbf{n}=\mathbf{1 , 3 3 6})$ & $\boldsymbol{p}$ \\
\hline Time to medical visit & $0: 46 \pm 0: 53$ & $0: 29 \pm 0: 36$ & $<.001$ \\
Green code & $0: 57 \pm 0: 59$ & $0: 40 \pm 0: 43$ & $<.001$ \\
Yellow code & $0: 43 \pm 0: 50$ & $0: 32 \pm 0: 38$ & $\mathrm{NS}$ \\
Red code & $0: 20 \pm 0: 28$ & $0: 16 \pm 0: 21$ & $<.001$ \\
Time of medical visit & $1: 37 \pm 2: 05$ & $1: 19 \pm 1: 09$ & .004 \\
Green code & $1: 36 \pm 2: 20$ & $1: 09 \pm 1: 03$ & $<.001$ \\
Yellow code & $1: 38 \pm 2: 02$ & $1: 22 \pm 1: 16$ & $\mathrm{NS}$ \\
Red code & $1: 21 \pm 0: 59$ & $1: 14 \pm 0: 50$ & $<.001$ \\
Total time in the ED & $2: 23 \pm 2: 17$ & $1: 48 \pm 1: 19$ & $<.001$ \\
Green code & $2: 33 \pm 2: 32$ & $1: 49 \pm 1: 12$ & $<.001$ \\
Yellow code & $2: 21 \pm 2: 14$ & $1: 54 \pm 1: 27$ & $\mathrm{NS}$ \\
Red code & $1: 41 \pm 1: 10$ & $1: 30 \pm 0: 56$ & .001 \\
LOS (days) & $9.0 \pm 7.8$ & $8.2 \pm 10.1$ & \\
\hline
\end{tabular}

At the further multivariate analysis, an independent association with mortality was maintained only for colour code of admission yellow and red (yellow: $\mathrm{OR}=2.5$ [95\% CI 2.06-3.03], $p<.001$, red: $\mathrm{OR}=17.1$ [95\% CI 13.6-21.5], $p<.001$ ), and, with a less extent, age $(\mathrm{OR}=1.02[95 \%$ CI 1.02-1.03], $p<.001)$ (see Table 3$)$.

Table 3. Multivariate analysis for primary objective (IHS)

\begin{tabular}{llll}
\hline & \multicolumn{1}{c}{ In-hospital mortality } \\
\hline OR & $\mathbf{9 5 \%} \mathbf{C I}$ & $\boldsymbol{p}$ \\
\hline Male & 1.02 & $1.02-1.03$ & $<.001$ \\
Daytime & 0.84 & $0.75-0.95$ & .006 \\
Yellow code & 0.77 & $0.67-0.89$ & $<.001$ \\
Red code & 2.5 & $2.06-3.03$ & $<.001$ \\
\hline
\end{tabular}

\subsection{Length of stay}

LOS (mean $8.9 \pm 8$ days, median seven days) was higher in subjects discharged alive than in deceased $(9 \pm 7.8$ vs. $8.2 \pm$ 10.1 days, $p<.001$ ). Due to the high variation of Standard Deviation, secondary to the non-normal distribution of LOS, we calculated also the median (M) and the interquartile range (IQR). Again, the difference was highly significant (M 7 and IQR 7 vs. M 5 and IQR 10.1, $<<.001$, for discharged alive and deceased, respectively).

Table 4. Univariate analysis for secondary objective (LOS)

\begin{tabular}{llll}
\hline & LOS $<$ 7 days $(\mathbf{n}=\mathbf{7 , 3 4 2})$ & LOS $>$ 7 days $(\mathbf{n}=\mathbf{5 , 8 9 5})$ & $\boldsymbol{p}$ \\
\hline Age (years) & $75.8 \pm 14.2$ & $77.6 \pm 12.6$ & $<.001$ \\
Daytime & $68.4 \%$ & $75.7 \%$ & $<.001$ \\
Nighttime & $31.6 \%$ & $24.3 \%$ & \\
Weekend & $27.2 \%$ & $24.7 \%$ & .001 \\
Weekday & $72.8 \%$ & $75.3 \%$ & \\
Holiday & $28.8 \%$ & $26.3 \%$ & .002 \\
No holiday & $71.2 \%$ & $73.7 \%$ & \\
Green code & $27.1 \%$ & $21.5 \%$ & $<.001$ \\
Yellow code & $66.4 \%$ & $72.6 \%$ & \\
Red code & $6.5 \%$ & $5.9 \%$ & \\
\hline
\end{tabular}

Published by Sciedu Press 
Univariate analysis showed that LOS $>7$ days was related to time of admission (daytime $75.7 \%$ vs. $68.4 \%$, nighttime $24.3 \%$ vs. $31.6 \%, p<.001$ ), WE or WD (WE: $24.7 \%$ vs. $27.2 \%$, WD $75.3 \%$ vs. $72.8 \%, p=.001$ ), and holidays (holidays: $26.3 \%$ vs. $28.8 \%$, no holidays $73.3 \%$ vs. $71.2 \%, p=.002$ ). Furthermore, LOS $>7$ days depended on both colour code of admission (green: $38.9 \%$, yellow: $46.8 \%$, red: $42.3 \%, p<.001$ ), and patients' age $(77.6 \pm 12.6$ vs. $75.8 \pm 14.2, p<.001$ ) (see Table 4). Thus, a longer LOS was associated with age, admission during daytime, WD and no holiday, and yellow code.

At the multivariate analysis (see Table 5), a significant correlation with a longer LOS was maintained only for yellow colour code $(\mathrm{OR}=1.36$; [95\% CI 1.26-1.48], $p<.001)$, and, with a less extent, for age (OR $=1.01$; [95\% CI 1.007-1.012], $p<.001)$.

Table 5. Multivariate analysis for secondary objective (LOS)

\begin{tabular}{llll}
\hline & \multicolumn{2}{c}{ Lenght of Stay $>\mathbf{7}$ days } \\
\hline & OR & $\mathbf{9 5 \%}$ CI & $\boldsymbol{p}$ \\
\hline Age & 1.01 & $1.007-1.012$ & $<.001$ \\
Daytime & 0.71 & $0.65-0.76$ & $<.001$ \\
Yellow code & 1.36 & $1.26-1.48$ & $<.001$ \\
\hline
\end{tabular}

\section{Discussion}

It is always rather complicated to try to analyze data and performances when considering the activity of an ED, a crucial node for hospital organization. Moreover, the time factor is important, since ED arrivals show also peculiar differentiated patterns depending on different diseases ${ }^{[17]}$.

The main finding of our study is that IHM and LOS are not strictly affected by a weekend effect but rather by clinical conditions, such as disease severity expressed by colour code, and age. In fact, multivariate analysis showed that both parameters are associated with daytime admission, which appeared to be a protective factor, in agreement also with Lee et al. ${ }^{[18]}$, who showed an increased IHM in patients admitted during the evening and night. Possibly, an earlier start of diagnostic procedures and treatment could impact patients' prognosis. Again, IHM rate was higher when admission occurred in post-office hours ${ }^{[8]}$ and during the holidays ${ }^{[19]}$. As for WE versus WD, although a high mortality in subjects admitted during the WE has been reported by several authors, with an estimated increase of risk between $10 \%$ and $32 \%{ }^{[14,15,20-22]}$, in our study there was a trend in which more patients admitted during the WE died than those admitted on $\mathrm{WD}$, but this was not confirmed by multivariate analysis. The results reported in the literature are not always consistent when considering the levels of hospital: the prognostic value of WE admission was identified more frequently in major teaching hospitals compared with nonteaching hospitals ${ }^{[23]}$, but no correlation between WE admission and IHM was found in patients admitted to tertiary care hospitals ${ }^{[24]}$.

As for LOS, in our study it was mainly dependent on patients' clinical conditions and, to a lesser extent, to age. LOS was higher in patients admitted with yellow colour code, probably due to extremely high mortality $(>25 \%)$ for patients admitted with red code. Moreover, LOS is also influenced by hospitalization during daytime, which seems to represent a protective factor. A study involving more than 45,000 patients admitted to different hospital departments, showed that hospitalization during WE (Friday, Saturday and Sunday) was associated with a longer LOS, and the same for admission during the afternoon and evening. In this study, however, the relationship between LOS and WE admission was not statistically significant for the medical department, but evident for general surgery, respiratory, and neurology departments ${ }^{[25]}$. The data are also inconclusive for admissions to the Intensive Care Unit (ICU). On the one hand, two studies did not show higher hospital mortality rate in patients admitted on WE or during off-hours in the United States and France, respectively ${ }^{[26,27]}$. On the other, an increased risk of death was found in patients admitted to an ICU over the weekend, but not during the nighttime, in the United States ${ }^{[28]}$. Finally, Singer et al. ${ }^{[16]}$ found that hospital mortality and 
LOS were associated with length of ED boarding (from $2.5 \%$ in patients boarded less than two hours to $4.5 \%$ in those boarding 12 hours or more). However, these latter results are not comparable with those of our hospital, where mean ED LOS is only $2+/-2$ hours, and probably different organization is involved.

\section{Limitations}

The main limitation of this study is given by the setting (single center), and by a retrospective design based on colour-code assessment. This since colour-code assessment represents subjective judgement, and no precise data, i.e., past medical history, presence of risk factors, medications assumed at home, physical examination on admission, were available. However, a major strength is given by the large sample size, well representative of the real world of the everyday hospital practice.

\section{Conclusions}

A series of studies confirmed a worst outcome for patients hospitalized on WE for several acute diseases ${ }^{[29-35]}$, so that the definition of weekend effect has been introduced. Generally, this weekend effect has been ascribed to factors related to medical organization, such as presence of a less experienced staff, lower availability of procedures and reduction in the surveillance to patients secondary to understaffing ${ }^{[4]}$. We aimed to focus on the mass of urgent patients that is managed in the ED and then admitted to internal medicine units. This cohort of patients is characterized by intermediate-high level of urgency ( $6 \%$ red code, $69 \%$ yellow code, $25 \%$ green code, 0 white code), and probably by the need for lower intensity of instrumental procedures immediately requested. Again, health organization is different in our country, compared with United States or United Kingdom, where the majority of studies on WE mortality have been performed. We have not substantial differences in the presence of senior trained doctors and availability of technological equipment between WD and WE. Of course, the number of doctors on duty is reduced during WE, but not the level of experience of the medical, nursing and technical staff on duty. To the best of our knowledge, this is the first study specifically addressed to evaluate some outcome indicators of ED patients admitted to internal medicine wards in Italy. Although several unmodifiable factors influence clinical outcome, such as disease severity expressed by colour code on admission and age, a striking weekend effect is not evident for in-hospital mortality nor hospital length-of-stay. It seems that our hospital organization, although more expensive in terms of energies of senior doctors who maintain the rotations despite the continuously decreasing staffing secondary to economic constraints, may warrant equal intensity of care along the entire week.

\section{Competing interests}

The authors declare that they have no competing interests.

\section{Acknowledgments and funding}

We are deeply indebted with Dr. Franco Guerzoni, Nucleo Aziendale Controlli, and Dr. Nicola Napoli \& Dr. Elena Forini, Programmazione e Controllo di Gestione, Azienda Ospedaliera-Universitaria, Ferrara, Italy, for their valuable and precious collaboration. This study has been supported, in part, by a scientific grant (FAR - Fondo Ateneo Ricerca) from the University of Ferrara (Prof. R. Manfredini).

\section{References}

[1] Muller JE, Stone PH, Turi ZG, et al. Circadian variation in the frequency of onset of acute myocardial infarction. N Engl J Med. 1985; 313: 1315-1322. PMid: 2865677. http://dx.doi.org/10.1056/NEJM198511213132103

[2] Manfredini R, Boari B, Bressan S, et al. Influence of circadian rhythm on mortality after myocardial infarction: data from a prospective cohort of emergency calls. Am J Emerg Med. 2004; 22: 55-59. http://dx.doi.org/10.1016/j.ajem.2004.08.014

[3] Casetta I, Granieri E, Fallica E, et al. Patient demographic and clinical features and circadian variation in onset of ischemic stroke. Arch Neurol. 2002; 59: 48-53. PMid: 11790230. http://dx.doi.org/10.1001/archneur.59.1.48 
[4] Casetta I, Granieri E, Portaluppi F, Manfredini R. Circadian variability in hemorrhagic stroke. JAMA. 2002; $287: 1266-1267$. PMid: 11886317. http://dx.doi.org/10.1001/jama.287.10.1266

[5] Gallerani M, Portaluppi F, Maida G, et al. Circadian and circannual rhythmicity in the occurrence of subarachnoid hemorrhage. Stroke. 1996; 27: 1793-1797. PMid: 8841332. http://dx.doi.org/10.1161/01.STR.27.10.1793

[6] Manfredini R, Portaluppi F, Zamboni P, et al. Circadian variation in spontaneous rupture of abdominal aorta. Lancet. 1999; 353: 643-644. http://dx.doi.org/10.1016/S0140-6736(98)05653-0

[7] Mehta RH, Manfredini R, Hassan F, et al. Chronobiological patterns of acute aortic dissection. Circulation. 2002; 106: 1110-1115. PMid: 12196337. http://dx.doi.org/10.1161/01.CIR.0000027568.39540.4B

[8] Manfredini R, Manfredini F, Boari B, et al. Seasonal and weekly patterns of hospital admissions for nonfatal and fatal myocardial infarction. Am J Emerg Med. 2009; 27: 1097-1103. PMid: 19931757. http://dx.doi.org/10.1016/j.ajem.2008.08.009

[9] Gallerani M, Boari B, Smolensky MH, et al. Seasonal variation in occurrence of pulmonary embolism: analysis of the database of the Emilia-Romagna region, Italy. Chronobiol Int. 2007; 24: 143-160. PMid: 17364585. http://dx.doi.org/10.1080/07420520601139755

[10] Dentali F, Ageno W, Rancan E, et al. Seasonal and monthly variability in the incidence of venous thromboembolism: a systematic review and a meta-analysis of the literature. Thromb Haemost. 2011; 106: 439-447. PMid: 21725580. http://dx.doi.org/10.1160/TH11-02-0116

[11] Willich SN, Lowel H, Lewis M, et al. Weekly variation of acute myocardial infarction: increased Monday risk in the working population. Circulation. 1994; 90: 87-93. PMid: 8026056. http://dx.doi.org/10.1161/01.CIR.90.1.87

[12] Manfredini R, Casetta I, Paolino E, et al. Monday preference in onset of ischemic stroke. Am J Med. 2001; 111: 401-403. http://dx.doi.org/10.1016/S0002-9343(01)00836-1

[13] Manfredini R, Citro R, Previtali M, et al. Monday preference in onset of Takotsubo cardiomyopathy. Am J Emerg Med. 2010; 28: 715-719. PMid: 20637389. http://dx.doi.org/10.1016/j.ajem.2009.04.023

[14] Bell CM, Redelmeier DA. Mortality among patients admitted to hospitals on weekends as compared with weekdays. N Engl J Med. 2001; 345: 663-668. PMid: 11547721. http://dx.doi.org/10.1056/NEJMsa003376

[15] Mohammed MA, Sidhu KS, Rudge G, et al. Weekend admission to hospital has a higher risk of death in the elective setting than in the emergency setting: a retrospective database study of national health service hospitals in England. BMC Health Services Research. 2012; 12: 87. PMid: 22471933. http://dx.doi.org/10.1186/1472-6963-12-87

[16] Singer AJ, Thode HC Jr, Viccellio P, et al. The association between length of emergency department boarding and mortality. Acad Emerg Med. 2011; 18: 1324-1329. PMid: 22168198. http://dx.doi.org/10.1111/j.1553-2712.2011.01236.x

[17] Manfredini R, la Cecilia O, Boari B, et al. Circadian pattern of emergency calls: implications for ED organization. Am J Emerg Med. 2002; 20: 282-286. PMid: 12098172. http://dx.doi.org/10.1053/ajem.2002.33000

[18] Lee KG, Vaithilingam I. A study of weekend and off-hour effect on mortality in a public hospital in Malaysia. Med J Malaysia. 2012; 67:478-482. PMid: 23770862.

[19] Smith S, Allan A, Greenlaw N, et al. Emergency medical admissions, deaths at weekends and the public holiday effect. Cohort study. Emerg Med J. 2013 Jan 23 [Epub ahead of print]. http://dx.doi.org/101136/emermed-2012-201881.

[20] Marco J, Barba R, Plaza S, et al. Analysis of the mortality of patients admitted to internal medicine wards over the weekend. Am J Med Qual. 2010; 25: 312-318. PMid: 20484660. http://dx.doi.org/10.1177/1062860610366031

[21] Freemantle N, Richardson M, Wood J, et al. Weekend hospitalization and additional risk of death: an analysis of inpatient data. J R Soc Med. 2012; 105: 74-84. PMid: 22307037. http://dx.doi.org/10.1258/jrsm.2012.120009

[22] Sharp AL, Choi H, Hayward RA. Don't get sick on the weekend: an evaluation of the weekend effect on mortality for patients visiting US EDs. Am J Emerg Med. 2013; 31: 835-837. PMid: 23465873. http://dx.doi.org/10.1016/j.ajem.2013.01.006

[23] Cram P, Hillis SL, Barnett M, et al. Effects of weekend admission and hospital teaching status on in-hospital mortality. Am J Med. 2004; 117: 151-157. PMid: 15276592. http://dx.doi.org/10.1016/j.amjmed.2004.02.035

[24] Khanna R, Wachsberg K, Marouni A, et al. The association between night or weekend admission and hospitalization-relevant patient outcomes. J Hosp Med. 2011; 6: 10-14. PMid: 21241035. http://dx.doi.org/10.1002/jhm.833

[25] Earnest A, Chen MIC, Seow E. Exploring if day and time of admission is associated with average length of stay among inpatients from a tertiary hospital in Singapore: an analytic study based on routine admission data. BMC Health Services Research. 2006; 6: 6. PMid: 16426459. http://dx.doi.org/10.1186/1472-6963-6-6

[26] Ensminger SA, Morales IJ, Peters SG, et al. The hospital mortality of patients admitted to the ICU on weekends. Chest. 2004; 126: 1292-1298. PMid: 15486395. http://dx.doi.org/10.1378/chest.126.4.1292

[27] Luyt CE, Combes A, Aegerter P, et al. Mortality among patients admitted to intensive care units during weekday day shifts compared with "off" hours. Crit Care Med. 2007; 35: 3-11. PMid: 17080000.

http://dx.doi.org/10.1097/01.CCM.0000249832.36518.11 
[28] Cavallazzi R, Marik PE, Hirani A, et al. Association between time of admission to the ICU and mortality: a systematic review and meta-analysis. Chest. 2010; 138: 68-75. PMid: 20418364. http://dx.doi.org/10.1378/chest.09-3018

[29] Kostis WJ, Demissie K, Marcella SW, et al. Weekend versus weekday admission and mortality from myocardial infarction. N Engl J Med. 2007; 356: 1099-1109. PMid: 17360988. http://dx.doi.org/10.1056/NEJMoa063355

[30] Saposnik G, Baibergenova A, Bayer N, et al. Weekends: a dangerous time for having a stroke? Stroke. 2007; 38: 1211-1215. PMid: 17347472. http://dx.doi.org/10.1161/01.STR.0000259622.78616.ea

[31] Aujesky D, Jimenez D, Mor GK, et al. Weekend versus weekday admission and mortality after acute pulmonary embolism. Circulation. 2009; 24: 962-968. PMid: 19204300. http://dx.doi.org/10.1161/CIRCULATIONAHA.108.824292

[32] Gallerani M, Imberti D, Ageno W, et al. Higher mortality rate in patients hospitalised for acute pulmonary embolism during weekends. Thromb Haemost. 2011; 106: 83-89. PMid: 21544321. http://dx.doi.org/10.1160/TH11-02-0068

[33] Gallerani M, Boari B, Manfredini F, et al. Weekend versus weekday hospital admissions for acute heart failure. Int J Cardiol. 2011; 46: 444-447. PMid: 21115205. http://dx.doi.org/10.1016/j.ijcard.2010.10.113

[34] Gallerani M, Imberti D, Bossone E, et al. Higher mortality in patients hospitalized for acute aortic rupture or dissection during weekends. J Vasc Surg. 2012; 55: 1247-1254. PMid: 22542339. http://dx.doi.org/10.1016/j.jvs.2011.11.133

[35] Gallerani M, Volpato S, Boari B, et al. Outcomes of weekend versus weekday admission for acute aortic dissection or rupture: a retrospective study on the Italian National Hospital Database. Int J Cardiol. 2013; 168:3117-3119. PMid: 23642591.

http://dx.doi.org/10.1016/j.ijcard.2013.04.065 